proptosis simulating orbital tumour. As a basis of discussion, I should like to suggest the following, though the list seems rather formidable. Examination of the urine, especially for sugar. Performance of a Wassermann reaction which, if negative, should be repeated after a provocative dose of salvarsan. Exclusion of tuberculous infection, if necessary, by a complement fixation reaction or one of the tuberculin tests. Differential blood count, and estimation of blood coagulation time. Careful search for focal infections and radiographic examination of teeth and sinuses. The history, of course, as in Harrison Butler's case, may be of paramount importance, and one must always remember the possibility of early Graves' disease. Finally, an exploratory operation might be indicated before proceeding to a radical extirpation of the complete contents of the orbit.

\title{
REFERENCES
}

1. Benedict, William M. and Knight, Mary S-Arch. of Ophthal., p. 582, Nov., 1923.

2. Birch-Hirschfeld.-Graefe-Saemisch Handbuch, 2nd edition, IX, pt. 1, $501,1910$.

3. Trotter, Wilfred.-Trans. Ophthal. Soc. of the U.K., p. 174, 1923.

4 Hine, Montague.-Ibid, p. 181, 1922.

5. Harrison, L. W.- "The diagnosis and treatment of venereal disease in general practice,", p. 275, 1918.

6. Taylor, Johnson.-Trans. Ophthal. Soc. of the U.K., p. 187, 1922.

7. Ewing.--"Neoplastic Diseases," 2nd edition, p. 248.

8. Cross, Richardson.-Trans. Ophthal. Soc. of the U.K., p. 253, 1916.

9. Lagrange.- - Traité des tumeurs de l'oeil et del'orbite," Paris, p. 464, 1904.

10. Williamson-Noble.-Trans. Ophthal. Soc. of the U.K., p. 189, 1922.

11. Lafon.-Bull.et Mém. Soc. Jranc. d'Ophtal., p. 502, 1908.

12. Marbaix and van Duyse. - "Pseudo-blastoma of the orbit," Arch. d'Ophtal., p. $466,1921$.

\section{TWO CASES OF CEREBRAL ANEURYSM CAUSING OCULAR SYMPTOMS WITH NOTES OF OTHER CASES}

BY

J. A. Conivay, D.S.O., M.C., M.D., F.R.F.P.S.(Glas.)

ASSISTANT SURGEON, GLASGOW EYE INFIRMARY

I HAVE had recently several interesting cases of cerebral aneurysm. Two of them, being of a type somewhat rare, are described at length, and notes of some other cases are appended. The occurrence of these cases has raised in my mind the whole question of cerebral aneurysm, and I have found it to be of interest to collect and collate the data of all my cases and many others that have gone to post-mortem examination in the Glasgow 
Royal Infirmary. In the hope that these details may be of interest and profit to others, I now publish the results of my experience. The two cases described at length were in the Royal Infirmary under Dr. J. M. Cowan, whom I now thank for help in the preparation of this article and for the generous loan of notes, photographs, and sketches. It is a curious fact, that when considering possible causes of cerebral symptoms, aneurysm of a cerebral vessel rarely suggests itself, and the following reasons have occurred to me, why this should be so. In the first place a cerebral aneurysm may exist and give rise to no symptoms that we can recognize clinically. Secondly, as this condition is often the cause of sudden serious symptoms, followed by rapid death, there is no opportunity to study the prodromal symptomatology. Thirdly, age gives no clue as to its probable presence or absence, as it is a condition which may be present at any age. Finally, I know of no particular diathesis or constitutional state which favours the existence of this condition, or would lead me to suspect its presence, as against other cerebral neoplasms. Therefore, it is true to say that cerebral aneurysm rarely gives opportunity for clinical study, and that this diagnosis is equally rarely hazarded.

Writers on this subject, as far as my knowledge goes, are unanimous that the condition is of frequent occurrence. Osler ${ }^{(1)}$ found 12 cases in 800 autopsies at the Montreal General Hospital. Newton Pitt's ${ }^{(2)}$ collection from Guy's Hospital gives 19 in 9,000 inspections. Bradford ${ }^{(3)}$ savs the condition is not uncommon, whilst Fearnsides ${ }^{(4)}$ says, "the presence of a saccular aneurysm on one of the basal cerebral arteries at necropsy is one of the commonest pathological findings."

In a search of the records of the Pathological Department of the Glasgow Royal Infirmary (permission for which was most willingly granted by Professor J. H. Teacher) I found 43 cases of undoubted cerebral aneurysm among 6,325 sections. A survey of the literature of this subject, reveals a plenitude of cases, and to add others to that number is unnecessary, but interest is given to my first case, by the fact that hemianopia formed the most prominent symptom throughout the illness. Bramwell(5) and Weir Mitchell(6) have published similar cases, but in a fairly extensive search of the English literature published during the last twenty years on this subject, I have been unable to discover any allusion to another case of this type.

Interest is given to the second case, by the fact, that in $\mathrm{my}$ experience, ocular symptoms in cases of cerebral aneurysm are not of common occurrence, unless following on a cerebral haemorrhage. 
The history of the first case is as follows :

Q.D., aged 23 years, a butcher, was shown by me at the May, 1923, Meeting of the Scottish Ophthalmological Club, as a case of pituitary tumour, in which great alleviation of symptoms had taken place. I saw the patient first on March 25, 1923, on account of curious symptoms connected with vision. He stated that he had suffered from pains in the head for the last eight months. The pain came on in attacks, and during the attacks the pain was intermittent in character. At the onset of his illness the pain started in the right temple, and with each succeeding attack it travelled further back, until it became fixed in the right occipital region. In this region it was localized for a month, and during this time he noticed that the vision of the right eye had failed. The pain then started in the left temple, and in repeated attacks travelled backwards in the same way. Lifting heavy weights, and impure atmospheres brought on the pain. Coincident with the onset of pain in the left temple, he noticed that the vision of the left eye was failing.

On the first examination he volunteered the statement, that when he looked at two people at a distance, one of them would disappear and reappear. At no time during his illness was there any vomiting, though at times he felt nausea. The family history was good. The father and mother are alive and in good health. There were nine children in the family, all of whom were still living and well, with the exception of one who died in infancy. There had been no miscarriages nor stillbirths. His social condition called for no comment. He came from a good home. In appearance he looked a healthy well-developed young man. On examining the eyes, the right pupil was found to be larger than the left. The pupil reflexes were normal, though somewhat sluggish to light for a young subject. Hippus was observed. Both discs were noticeably pale. Right vision equalled hand movements. Left vision equalled fingers at six feet. The visual fields showed bitemporal hemianopia (Chart 1). A tentative diagnosis of pituitary tumour was made, and I sent him to Dr. John Cowan, Glasgow Royal Infirmary, in whose wards I have the privilege of working.

Examination of the general system did not reveal much to help us towards a diagnosis. The patient was apparently healthy in every other respect. The Wassermann reaction (blood and cerebro-spinal fluid) was returned as negative. The blood pressure was systolic 115 , diastolic 65 . The $\mathrm{X}$-ray report read as follows : "There appears to be some expansion of the sella Turcica, together with thinning of the floor. There is no evidence of bone erosion to indicate a malignant growth."

During his residence in the Royal Infirmary, he became quite blind in both eyes, and there followed a period during which it 


\section{Cerebral Aneurysm}

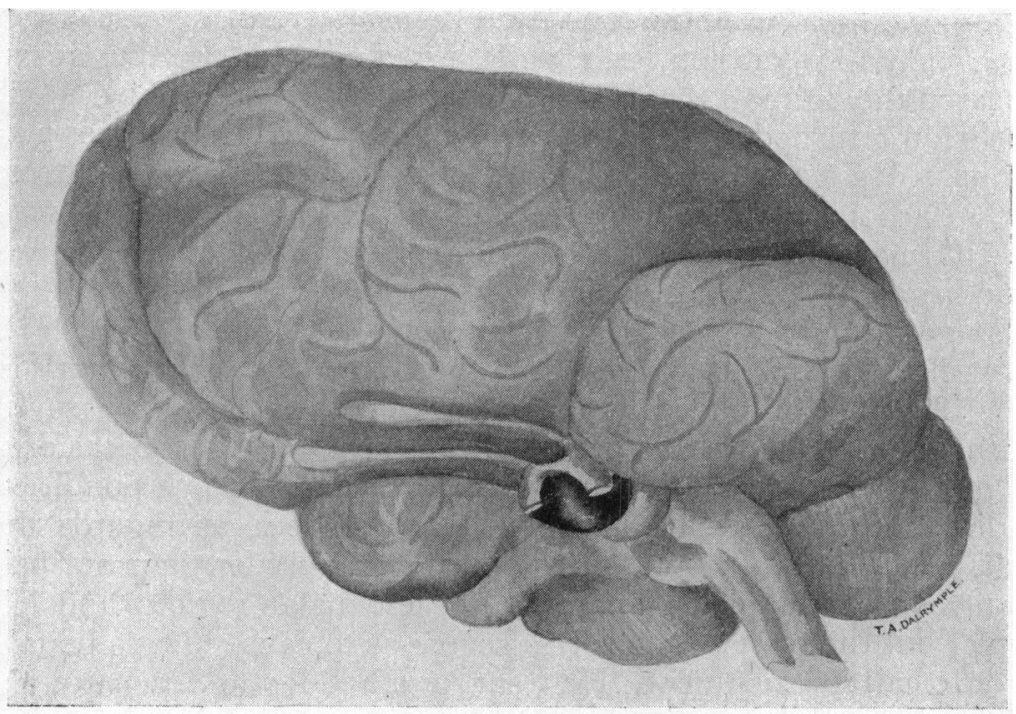

CASE 1.

(1) Aneurysm as seen on opening calvarium and lifting up brain.

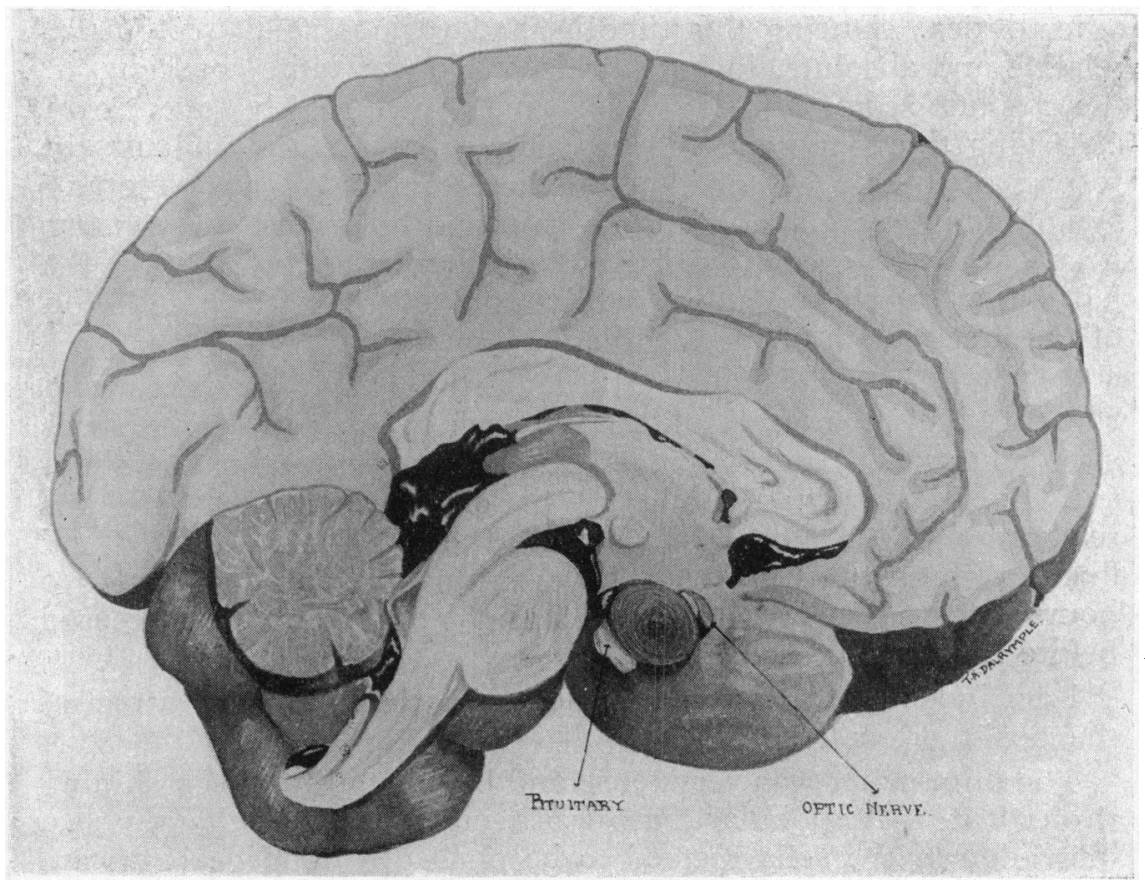

(2) Diagramatic antero-posterior mesial section showing anatomical relationship of aneurysm.

ㅇ

을 
was impossible to examine the visual fields. Mr. Pringle saw him with a view to operation, and while agreeing with the diagnosis, expressed the opinion that it was not a suitable case for operation. The vision returned to a slight degree in each eye but progress was minimal. He was discharged from the Royal, and at my request Dr. J. Barbour Stewart admitted him to his beds in the Glasgow Eye Infirmary for further observation. Soon after admission his vision began to improve sufficiently to permit of investigation of the fields again, and a series of charts was obtained, taken at intervals of a week. He was discharged from the Glasgow Eye Infirmary in June, 1923, and attended as an out-patient until his death seven months later. During this period he was seen on many occasions. His general health continued satisfactory, and the eye condition steadily improved. The notes in his case-sheet, as regards the fundi, state that both optic discs are definitely paler than normal. $\mathrm{He}$ always complained of pain in the left malar region, and left temple, but the pain was never so severe as to cause him to be laid up, or to call for treatment. He went for a holiday to Scarborough, and though, on advice, he did not indulge in any strenuous exercise, still long country walks caused him no inconvenience. Soon after his return from holiday, he resumed his work as a butcher. He refrained from lifting any heavy weights, but was quite fit for his other duties. During this time he had various small scotomata, relative and absolute, in both fields. He was quite conscious of the absolute scotomata, as by this time he was highly educated in observing this symptom, but he easily overcame any difficulty in respect of these. At no time did he complain of, nor were any symptoms observed, pointing to irritation of a motor or sensory nerve, with the exception of the slight headache and pain in the left cheek, referred to above, which pointed to an irritative lesion of the first branch of the fifth nerve.

On the morning of January 12, 1924, the patient was bright and cheerful, and took his breakfast and went to work in his butcher's shop as usual. His brother left the back apartment of the shop, and on his return found the patient unconscious. He was readmitted to the Royal Infirmary. The pupils were dilated and fixed. Temperature $97^{\circ} \mathrm{F}$. He was unconscious and died two hours later. Twenty minutes elapsed after respirations ceased before the heart ceased.

I am indebted to Professor Teacher for the following extract of the post-mortem record.

The dura mater was very tense and blood could be seen shining through it. A globular mass was seen filling the sella Turcica. The edge of the sella seemed to be pushed a good deal forward and the optic nerves diverged forward somewhat round the sides 
of the mass which filled the sella. The nerves were bent and spread out. The mass was readily dissected out of the sella, and the pituitary, normal in size and appearance, was found lying under it, and rather to the back of the sella. It was easily freed from the widened sella. The posterior clinoid processes stood up very sharply behind, and their anterior surfaces seemed to have been reduced in volume, but everywhere the dura was intact. The processes were not broken. The sella Turcica was considerably enlarged, and perhaps a little deepened. The ends of the carotid arteries lay exposed in the sides of the cavity. The anterior part of the interpeduncular space was occupied by a globular mass, which appeared to be exactly in the middle line, but on careful examination was found to lie a little more to the right. On section the mass was found to be an aneurysm, completely filled with laminated clot. This was of brown colour and was old. The mass was clearly an aneurysm healed by the natural process of thrombosis. In the cut section it measured $2.1 \mathrm{cms}$. in the anteroposterior, and 1.6. cms. in the up and down directions. It was about the size of a marble. The blood-vessels of the circle of Willis were normal on the left side. On the right side the aneurysm was attached to the middle cerebral on its median and upper aspect. The posterior communicating branch was swollen to a spindle-shaped aneurysm about $0.5 \mathrm{~cm}$. wide. It was soft and thrombosed. No other aneurysm was found, but dissection was limited. The source of the bleeding was therefore not made out. The infundibulum lay on the left side of the aneurysm. The optic nerve roots and chiasma were spread out on the front of it and slightly flattened.

\section{Discussion of the Case}

Beadles $^{(7)}$, who collected 555 cases of intracranial aneurysm from the literature and the museums, divided the cases into four groups. In the largest group (46 per cent.) death ensued suddenly from an apoplectiform seizure without any preceding symptoms of cerebral origin. In the second group (20 per cent.) symptoms of cerebral disturbance, but of ten very slight and equivocal, occurred and were followed by an apoplectiform seizure. In the third group (16 per cent.) cerebral symptoms alone were present. In the last group (16 per cent.) the aneurysm was merely an accidental finding in a case where death had occurred from causes quite apart from the aneurysm. The case which has been described falls into Beadles' second group, but it falls into that rarer class still in which hemianopia occurs as a symptom. The fields of vision make an interesting study, and the following are the steps in the progress of the case. 
Chart 1. March 26, 1923.-The left field shows blindness of the temporal half. The right field shows blindness of complete lower half, and segmental defect of upper half. Diagnosis of probable pituitary tumour made. Admitted to Royal Infirmary. Fields gradually become smaller until complete blindness supervenes.

Chart 2. May 11, 1923.-Admitted Glasgow Eye Infirmary. Complete bitemporal hemianopia with great contraction of the nasal fields.

Chart 3. May 25, 1923.-Nasal fields show increase in size. Temporal fields still blind.

Chart 4. June 1, 1923.-A large area in right temporal field has recovered vision. Complains of diplopia. Tested with Maddox Rod, showed a paresis of left internal rectus, i.e., a third nerve involvement.

Chart 5. June 8, 1923.-Dismissed from Glasgow Eye Infirmary. V.R. 6/12; V.L. 6/60. Right field shows a small absolute scotoma around the blind spot, with a larger relative scotoma below, and continuous with the first.

Chart 6. January 9, 1924. - These fields were taken three days before his death. The right field is normal in extent, and except for a small absolute scotoma, which makes an enlargement of the blind spot, is free from defect. The left field shows slight peripheral contraction, and two large relative scotomata. One of these is central in position, the other is continuous with the upper area of peripheral blindness. V.R. $6 / 9$; V.L. $6 / 12$.

It might be thought that the observation of this clinical fact, namely, the clearing up of the visual fields, would have shaken our confidence in the diagnosis, but it is known that changes in the fields in cases of pituitary tumour do occur. The direction of growth of the tumour may become changed, and pressure originally exerted on the chiasma, may become directed elsewhere, thus relieving to a greater or less extent the hemianopic symptoms. On this account the prognosis given was guarded and serious. As subsequent examination proved, it was not a case of tumour of the pituitary body, so that some other explanation must be sought for to account for the alleviation of the visual symptoms. The theory is put forward here, that the improvement in his visual fields, coincided with the thrombosing of the aneurysm. There is no evidence to prove this, but the behaviour of aneurysms elsewhere, when undergoing "cure" is recalled. Clotting of the blood in an aneurysm, usually brings about relief of the pressure symptoms. The fibrin from the blood becomes gradually deposited in a laminated manner on the walls of the sac, so that the aneurysm is completely consolidated, and subsequently by condensation and shrinking becomes converted into a small nodular mass of fibrous 

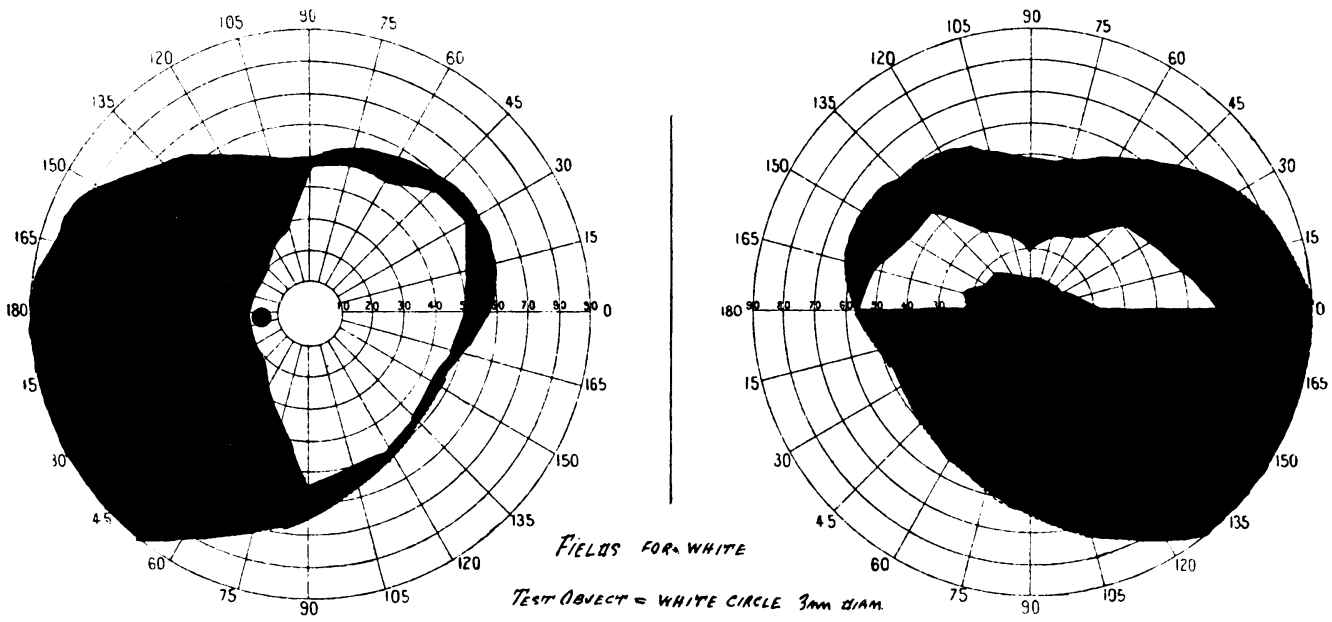

CHART 1.

tissue. It may well be that a similar chain of events had taken place here and, due to the lesser space occupied by the aneurysm when thrombosed, as contrasted with its bulk when blood was circulating through it, pressure on the chiasma was relieved. Up to the time of the first manifestation of improvement of his symptoms, he had received no drug treatment, treatment having consisted simply of rest in bed.
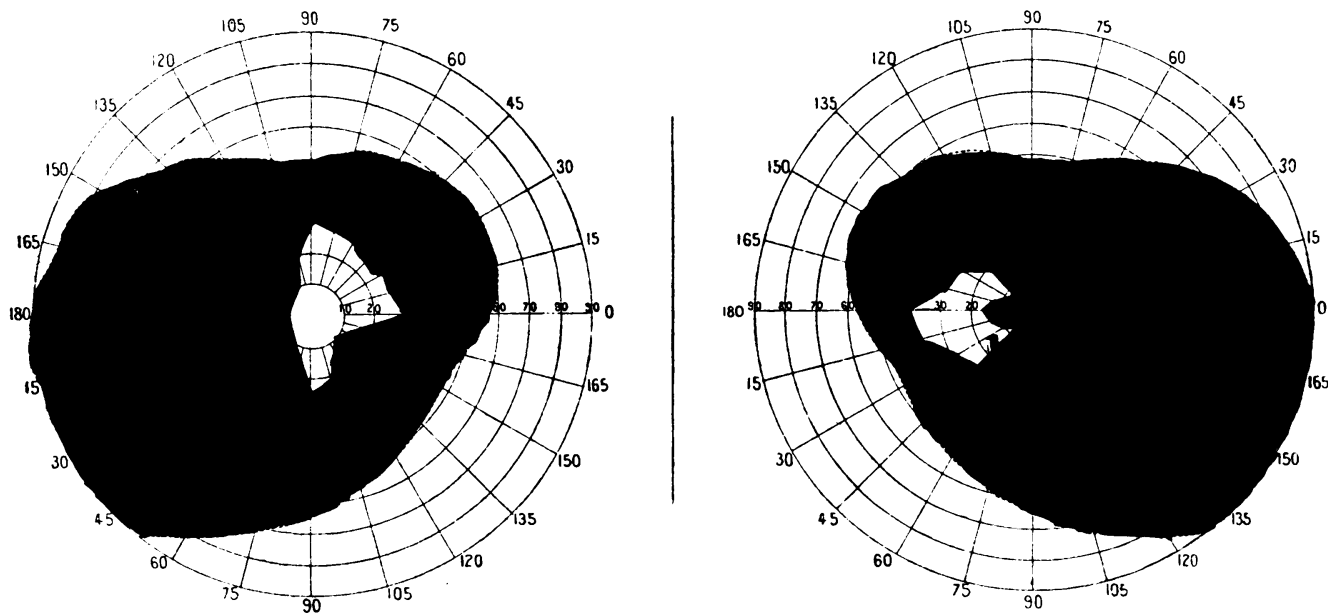

CHART 2. 

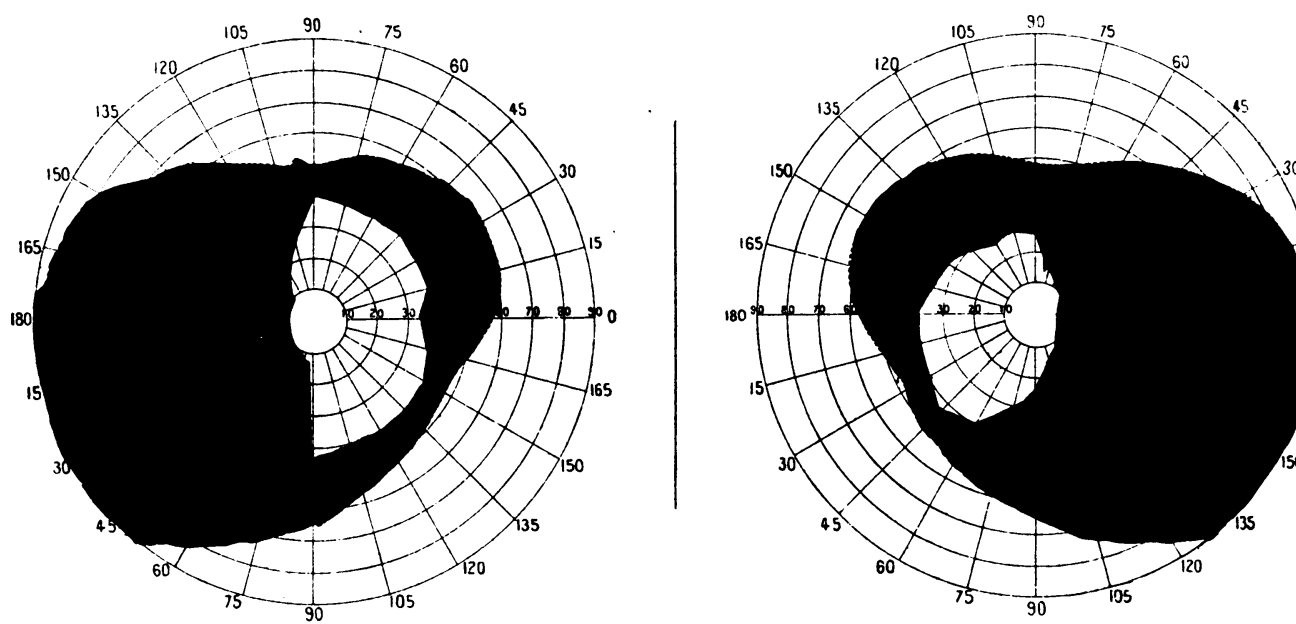

Chart 3.

Another interesting observation in the case is the post-mortem note that "the sella Turcica was considerably enlarged and perhaps a little deepened." This bears out the X-ray report which stated "there appears to be some expansion of the sella Turcica, together with thinning of the floor. There is no evidence of bone erosion to indicate a malignant growth." Examination of the plate taken in conjunction with the clinical evidence of the visual fields, .
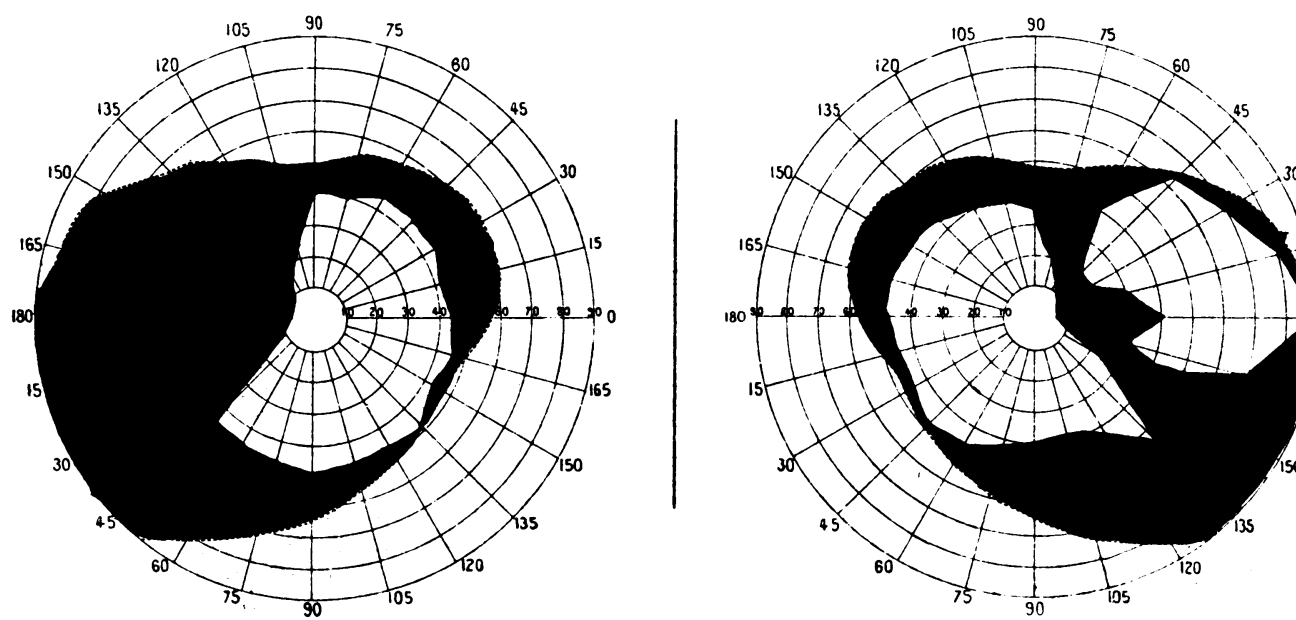

Chirt 4. 

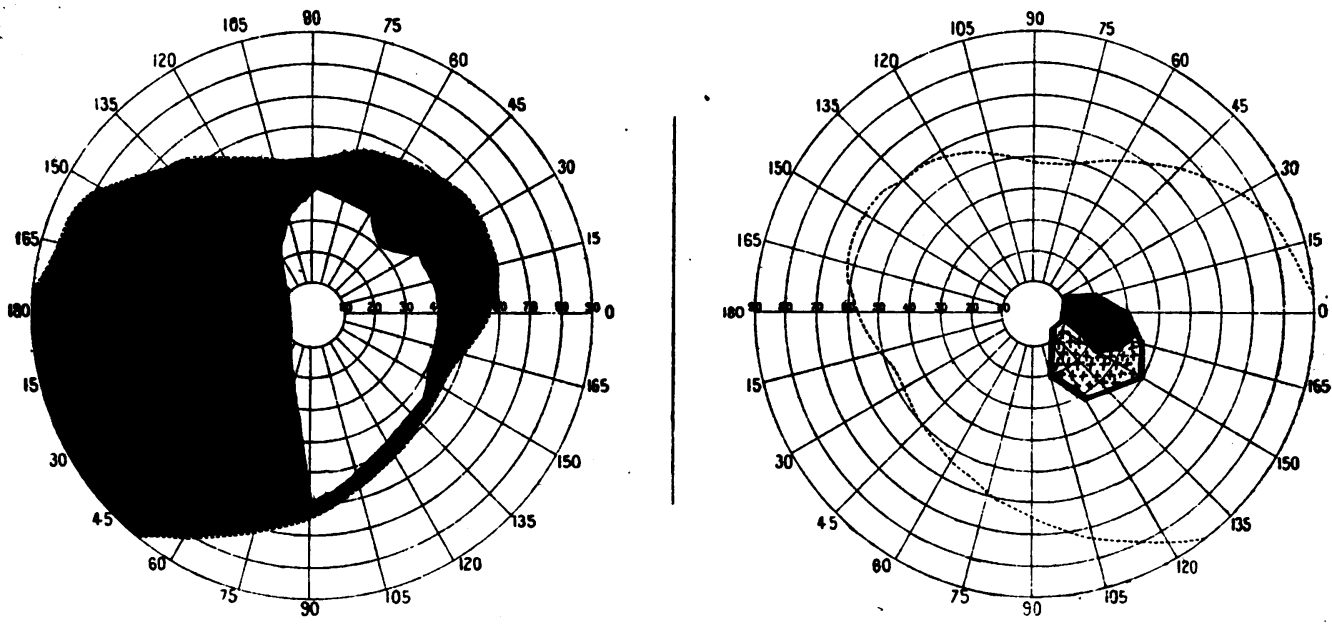

Chart 5.

seemed to confirm the diagnosis of a hyperplasia of the hypophysis. The fact that an aneurysm may cause an increase in the size of the sella must be borne in mind, as witness Oppenheim ${ }^{(8)}$ who quotes Bramwell as saying "it is a remarkable fact that aneurysm of the carotid may cause erosion of the sella Turcica."

One procedure, as an aid to diagnosis, we neglected, was to make a microscopical examination of the cerebro-spinal fluid. We
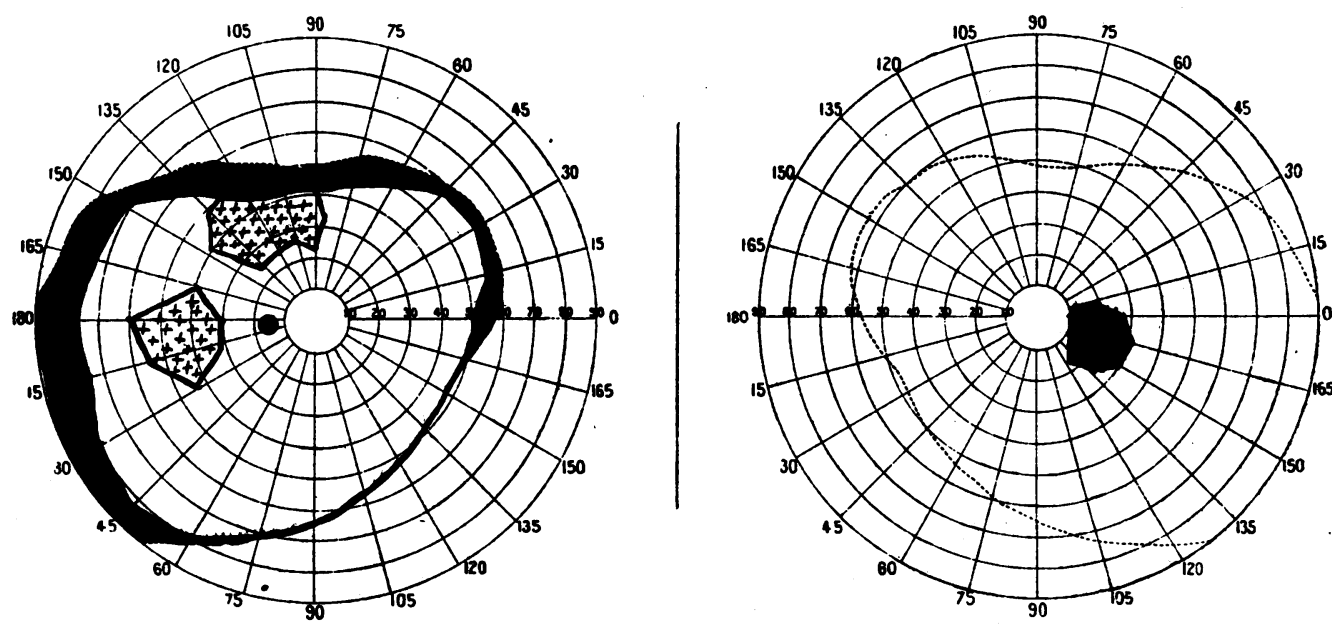

Chart 6. 
contented ourselves with an examination for the reaction of Wassermann. Oppenheim ${ }^{(8)}$ states that an intrameningeal haemorrhage caused by rupture may be demonstrated by changes in the cerebro-spinal fluid, found on lumbar puncture, and the diagnosis may be made in this way.

There was nothing in the history of our patient to suggest that an irritative haemorrhage, due to leaking from an aneurysm, had taken place, and there is no mention of such having occurred in the post-mortem report, so that this procedure would not have helped. Parenthetically, I may remark that the same author states that in this type of case, lumbar puncture is absolutely prohibited due to the danger of causing sudden rupture of the aneurysm.*

It is interesting to observe that the Wassermann reaction of the blood and the cerebro-spinal fluid was negative. The family history and the clinical evidence of the case were all against syphilis as being the causal agent. Fearnsides ${ }^{(4)}$ says of syphilis in the aetiology of cerebral aneurysm, that our views with regard to infection with the spirochaete need revision, meaning thereby that syphilis is not the common cause it was formerly suspected to be. My experience of this and other cases, leads me to agree with this opinion. But the chief point I wish to bring out, is that there was nothing in my case to suggest that he was suffering from aneurysm of a cerebral vessel as against any other form of neoplasm, and the conclusion of other writers on this subject is again borne out, that diagnosis of this condition during life is practically impossible. Beadles ${ }^{(7)}$ at the conclusion of his lecture to the Royal College of Surgeons on this subject, says "if there is one sign to which attention might be drawn, it is the occasional intermittent character of the symptoms." And the protean character of this disease was well shown in the case under discussion.

The history of the second case is as follows :

Mrs. N., aged 40 years, was admitted to the Glasgow Royal Infirmary on January 31,1921 . The patient complained of pain in the back of the neck, headache, dizziness, and defective vision. She stated that the pain had troubled her for two years, com-

*When I wrote this, Symonds'(9) very informative paper on subarachnoid spontaneous haemorrhage had not been published, and I was not aware of a method of procedure of examination of the cerebro-spinal fluid which he describes in detail, and to which I recommend readers interested to have recourse. In this paper he draws attention to a very useful distinction in the appearance and behaviour of the cerebro-spinal fluid into which blood had percolated from a subarachnoidal haemorrhage, and the features to be observed in the cerebro-spinal fluid contaminated by the accidental injury of a vein during lumbar puncture. The method of procedure is simple and it seems to me that in cases of leaking aneurysms much valuable information could be gained by adopting it. 
mencing after a confinement. It was first situated over the left lower jaw, then she experienced it worst over the left temporal region, and finally, the left side of the face generally became involved. The pain came on in attacks, which lasted for several days, followed by dizziness, which caused her to walk in a drunken

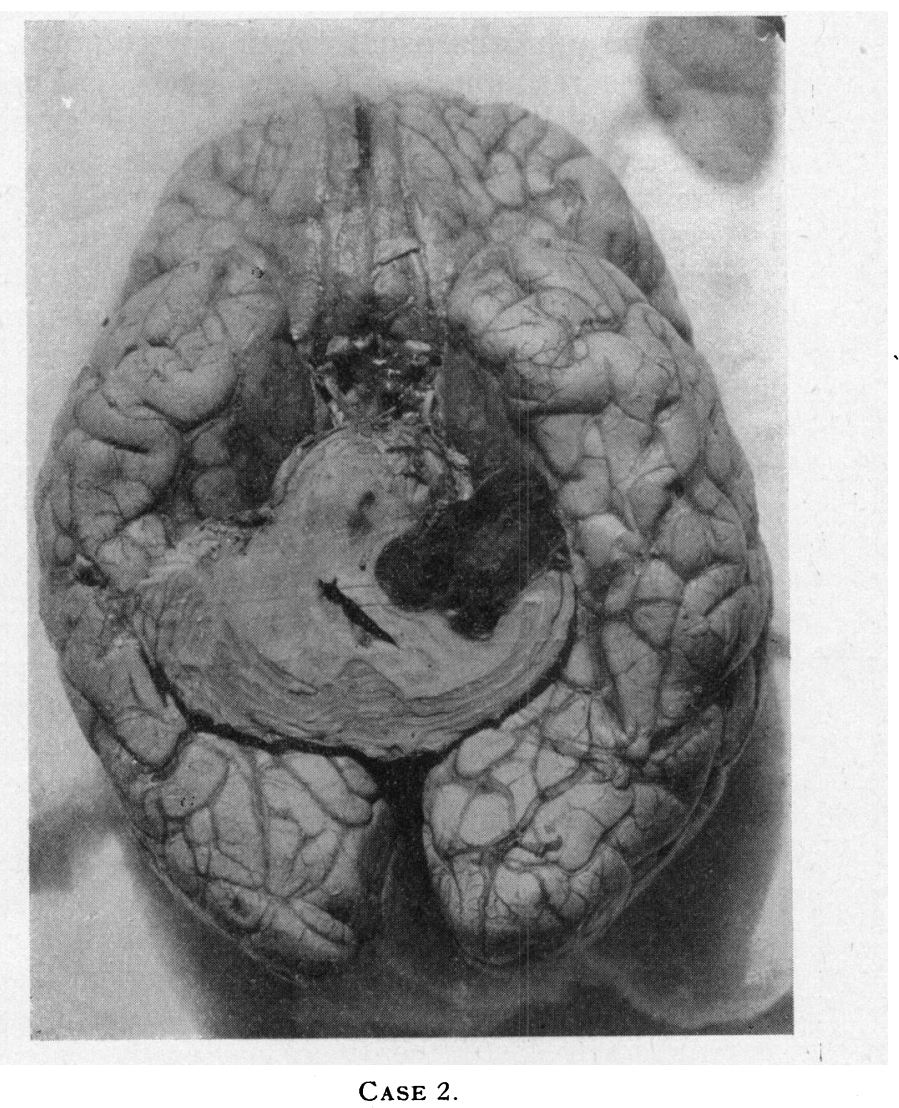

Section of cerebellum showing aneurysm.

fashion. Shortly before admission to hospital the pain had travelled to the back of the neck. About two weeks previous to admission she suddenly experienced great failure of vision.

With the exception of bronchitis in childhood, and "bilious attacks" during the last two years, she had always had good health. She had had six children, and perhaps one miscarriage.

On examination she looked older than her years. The heart was normal, and the pulse regular and of good pressure and 
quality. It was noticed that the brachials were tortuous, and the arteries generally, easily palpable. The lungs were normal. The examination of the nervous system may be put shortly as follows : On admission the patient was conscious, with clear speech and considerable vocabulary. Later she became stuporose. There was a right facial palsy, and paresis of the left arm and leg. The right pupil was larger than the left. The pupil reactions to light, accommodation, and the consensual reaction were normal at first. Later none of these reactions could be elicited. There was a noticeable weakness of both external recti. Double optic neuritis was present, at first more marked in the right eye.

The Wassermann reaction of the blood was negative. Examination of the cerebro-spinal fluid showed no organisms, but red blood corpuscles were abundant. A diagnosis of cerebellar tumour was made. She gradually became weaker in hospital. On February 23, 1921 Cheyne-Stokes respirations appeared, and she died the same day. I am indebted to Professor Teacher, for the following note on the post-mortem examination. "The inner and outer tables of the left occipital bone were completely eroded away, and the surface of the brain could be felt through the scalp. There was evidence of old haemorrhage over the cerebellum. Section of the brain proves the tumour to be an aneurysm of the left vertebral artery, originating just within the cranium. The aneurysm invaded the cerebellum chiefly, causing pressure on the area of the occipital bone where the erosion had taken place. The tumour measured one and a half inches in three diameters. Atheroma was present to a marked degree in the vertebral and posterior cerebral vessels, but examination of the aorta for evidence of vascular syphilis was made, with negative result. The aneurysm had not ruptured."

In connection with these cases, a search for similar cases was made in the post-mortem journals of the Pathological Department of the Glasgow Royal Infirmary. All the records of post-mortem examinations during the last fifteen years and such clinical records as came within the purview of the inquiry, were examined. In all 6,325 records were examined and 43 cases of cerebral aneurysm were found. In a search of this kind it is hard to decide, where to draw the line, as to which cases shall be included and which excluded. I quite recognize that there is a large class of dilatations existing, which the clinician would never regard as aneurysms, but which are noted on post-mortem examinations. I have only included those cases which could be readily recognized by the naked eye. For this reason my figures cannot be relied upon to give a true indication of the frequency of this condition. Another factor which militates against accuracy is that in the total number of post-mortem examinations, the head was not opened in every 
case. Regarding the 43 cases noted, certain data are tabulated below. It will be observed that some of the clinical records are scanty. This is due to the fact that not a few of the patients were picked off the street in coma, and no history was available.

Of the total number of cases of cerebral aneurysm that went to post-mortem examination, 24 were males and 19 females. The oldest was a man of $i 2$ years, and youngest that of a subject (age unstated) described as a young boy. Taking various arbitrary base lines, we notice that under 50 years of age, 34 cases occurred; under 45 years, 28 cases; under 40 years, 19 cases; and, a most significant fact, under 25 years of age, 10 cases occurred, or nearly 25 per cent. of the total number. The records show that the great majority died from sudden apoplexy, without any prodromal symptoms. Fifteen nevertheless showed some warning cerebral symptoms, usually headache and vomiting, but of this 15 , in only $\tau$ cases did the symptoms antecede death by more than a few days. All died of cerebral haemorrhage, with the exception of Mrs. N., one of the two cases described at length. With the exception of 4 cases all died of the rupture of the aneurysm. Of these 4 cases, 3 died of the rupture of another cerebral vessel, and one from intracranial pressure. Many of the cases showed ocular symptoms after the onset of cerebral haemorrhage, e.g., conjugate deviation, unequal pupils, etc., but with the exception of the cases of Q.D. and Mrs. N. there is no record of the aneurysm per se giving rise to ocular symptoms.

In no case was was the existence of cerebral aneurysm ventured as a possible cause of death. In very few cases is there any record of the Wassermann reaction. This can be explained by the fact that the majority were admitted in coma and death ensued rapidly. However it is to me a surprising observation, in how few cases is there any mention of syphilis of the vessels. The usual postmortem note is that the vessels, as far as could be observed, were healthy.

Regarding the question of the vessel most frequently affected in cerebral aneurysm, I have drawn up a table illustrating this point. As will be seen, one or other branch of the middle cerebral, in the great majority of cases, is the vessel involved. Some observers have worked out a majority in favour of the left middle cerebral, and although this vessel was affected most frequently in our series of cases, still the difference between the frequency of the left and the right is too slight for the basis of any conclusion. In two cases only in the series were two different vessels affected with aneurysm, thus the total number of aneurysms in this table amounts to 45 . Where there were several aneurysms on one vessel, this naturally counted as one vessel affected. 


\section{Table Showing Frequency of Vessels Affected.}

$\begin{array}{llllllr}\text { Right middle cerebral } & \ldots & \ldots & \ldots & \ldots & 10 \\ \text { Left middle cerebral } & \ldots & \ldots & \ldots & \ldots & \ldots & 11 \\ \text { Left ant. cerebral } & \ldots & \ldots & \ldots & \ldots & \ldots & 6 \\ \text { Right ant. cerebral } & \ldots & \ldots & \ldots & \ldots & \ldots & 7 \\ \text { Sylvian artery ... } & \ldots & \ldots & \ldots & \ldots & \ldots & 3 \\ \text { Ant. communicating } & \ldots & \ldots & \ldots & \ldots & \ldots & 4 \\ \text { Basilar artery ... } & \ldots & \ldots & \ldots & \ldots & \ldots & 3 \\ \text { Vertebral artery } & \ldots & \ldots & \ldots & \ldots & \ldots & 1\end{array}$

With reference to the question of the causation of aneurysm in these cases, it will be seen from the table appended, that out of the total of 43 cases, no less than 25 cases are regarded as showing no sign of vascular or cardiac diseases, or other sign of a causal agent. Having knowledge of the work of Turnbul(10), I must conclude that these aneurysms are of congenital origin. Aneurysms of non-inflammatory origin are due to a degeneration of the media, he states, and this is frequently associated with generalized arterial degeneration and cardiac hypertrophy. In a number of cases, however, intracranial aneurysms belonging to the non-inflammatory group are discovered in young persons without evidence of cardio-vascular disease. Turnbull has put forward the explanation, that in these cases the formation of a breach in the media is due to an inborn defect in the arterial wall, and this explanation is of general acceptance.

Of the above-mentioned 25 cases, which for want of positive evidence to the contrary, I regard as congenital cases, four cases have no age mentioned, being described simply as "boy," "young man," "young woman," and "middle age." Leaving these cases out of count, we have 21 cases left, in which the age is definitely stated, and which may be considered to be due to congenital defect. The average age of this group is 31 years. This average age incidence is interesting, as Fearnsides found the average age to be 38 years.

Since writing the above, Symonds ${ }^{(9)}$ has published a paper on subarachnoid haemorrhages, and with reference to this particular question, I cannot do better, than quote his own words. He says ".... and in this connection it is interesting to compare the age incidence of the group under discussion with that of Fearnsides' group of 15 cases of intracranial aneurysm, which in virtue of the absence of any other signs of cardiac or vascular disease, were considered to be due to congenital defect in the media. In the present group of 41 cases, the age incidence is 30 , in Fearnsides' 15 cases the average age was 38 years. The correspondence is close." 
Cerfbrat: Aneurysm

\begin{tabular}{|c|c|c|c|c|c|c|c|c|}
\hline 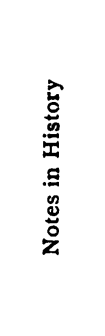 & 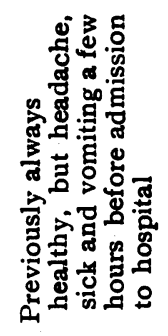 & 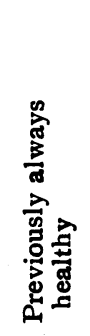 & 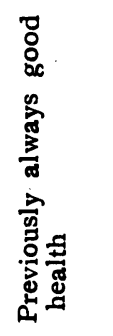 & 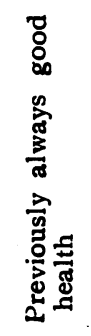 & 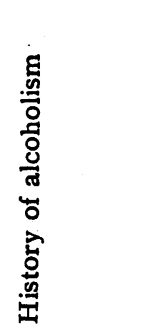 & 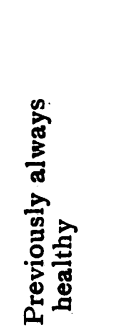 & 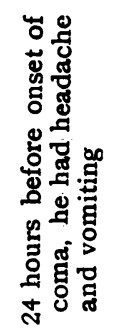 & 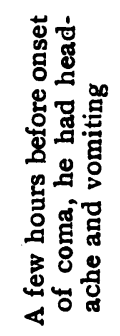 \\
\hline 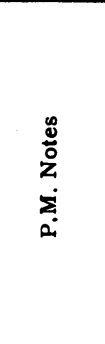 & 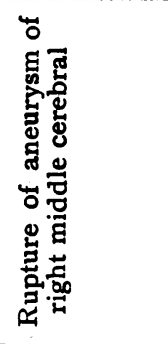 & 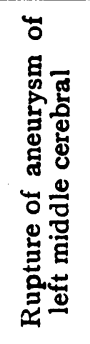 & 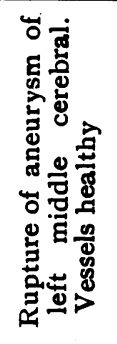 & 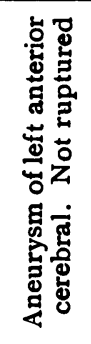 & 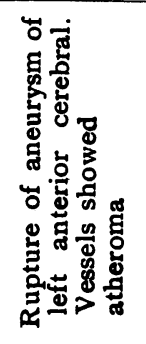 & 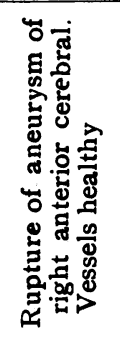 & 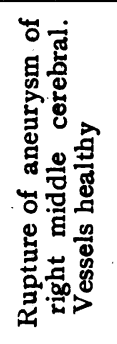 & 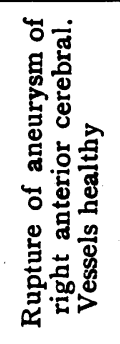 \\
\hline 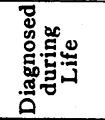 & 1 & 1 & 1 & 1 & 1 & 1 & 1 & 1 \\
\hline 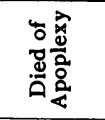 & + & + & + & + & + & + & + & + \\
\hline 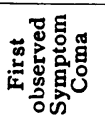 & 1 & + & + & + & + & + & 1 & 1 \\
\hline 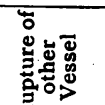 & 1 & 1 & 1 & + & 1 & 1 & 1 & 1 \\
\hline 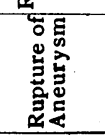 & + & + & + & 1 & + & + & + & + \\
\hline 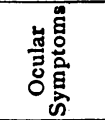 & 1 & 1 & 1 & 1 & 1 & 1 & 1 & 1 \\
\hline 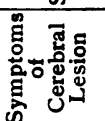 & + & 1 & 1 & 1 & 1 & 1 & + & + \\
\hline : & $\tilde{\sim}$ & $\stackrel{\sim}{\sim}$ & o & 우 & 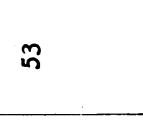 & 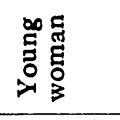 & $\hat{N}$ & ஜ \\
\hline ڤ̆ & $\Sigma$ & 山 & $\Sigma$ & $\Sigma$ & $\Sigma$ & a & $\Sigma$ & $\Sigma$ \\
\hline 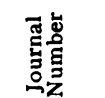 & $\frac{q}{a}$ & 옴 & $\begin{array}{l}\text { ळ్ } \\
\text { \%ু }\end{array}$ & $\vec{\circ}$ & 옹 & $\frac{8}{8}$ & 寓 & 命 \\
\hline
\end{tabular}

음 


\begin{tabular}{|c|c|c|c|c|c|c|c|c|}
\hline 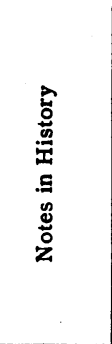 & 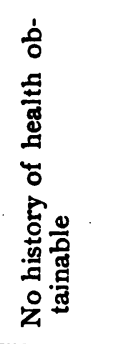 & 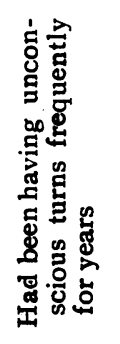 & 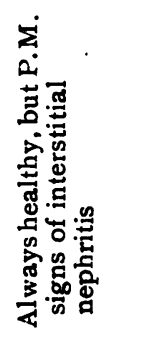 & 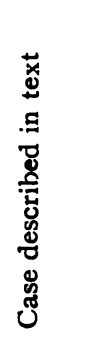 & 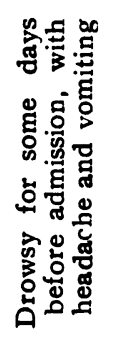 & 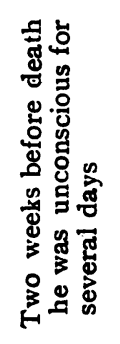 & 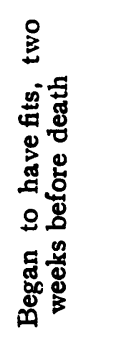 & 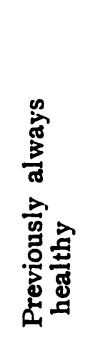 \\
\hline 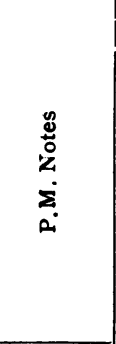 & 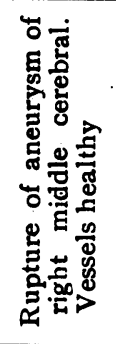 & 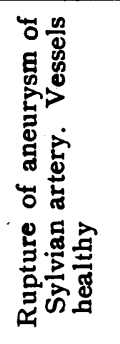 & 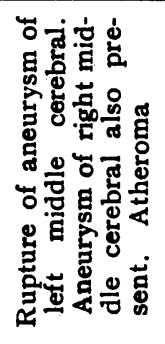 & 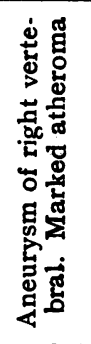 & 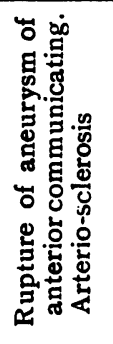 & 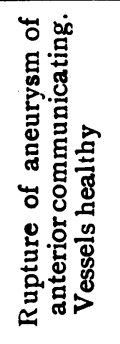 & 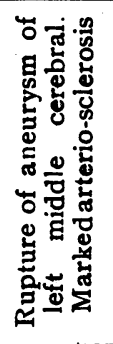 & 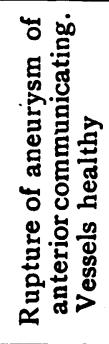 \\
\hline 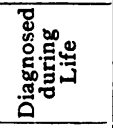 & $1^{\prime}$ & 1 & 1 & 1 & 1 & 1 & 1 & 1 \\
\hline 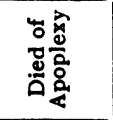 & $\dot{t}$ & + & + & 1 & + & + & + & + \\
\hline 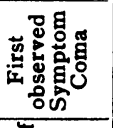 & + & 1 & + & 1 & 1 & 1 & 1 & + \\
\hline 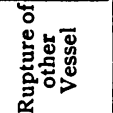 & 1 & 1 & 1 & 1 & 1 & 1 & 1 & 1 \\
\hline 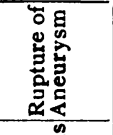 & + & + & + & 1 & + & + & + & + \\
\hline 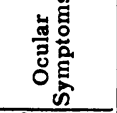 & 1 & 1 & 1 & + & 1 & 1 & 1 & 1 \\
\hline 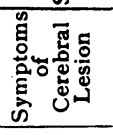 & + & + & 1 & + & + & + & + & 1 \\
\hline 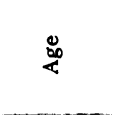 & 节 & $F$ & ㅇ & q & $g$ & $\stackrel{\infty}{\infty}$ & F & F \\
\hline ڤ్ & $\Sigma$ & 出 & $\Sigma$ & 山 & w & $\Sigma$ & $\Sigma$ & 盾 \\
\hline 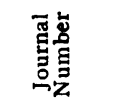 & $\begin{array}{l}\text { o. } \\
\text { o. }\end{array}$ & 응 & $\stackrel{2}{\alpha}$ & 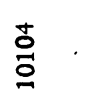 & $\stackrel{\bar{g}}{\stackrel{g}{g}}$ & 。ㅇํㅇ & 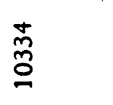 & 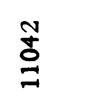 \\
\hline
\end{tabular}


Cerebral Aneurysm
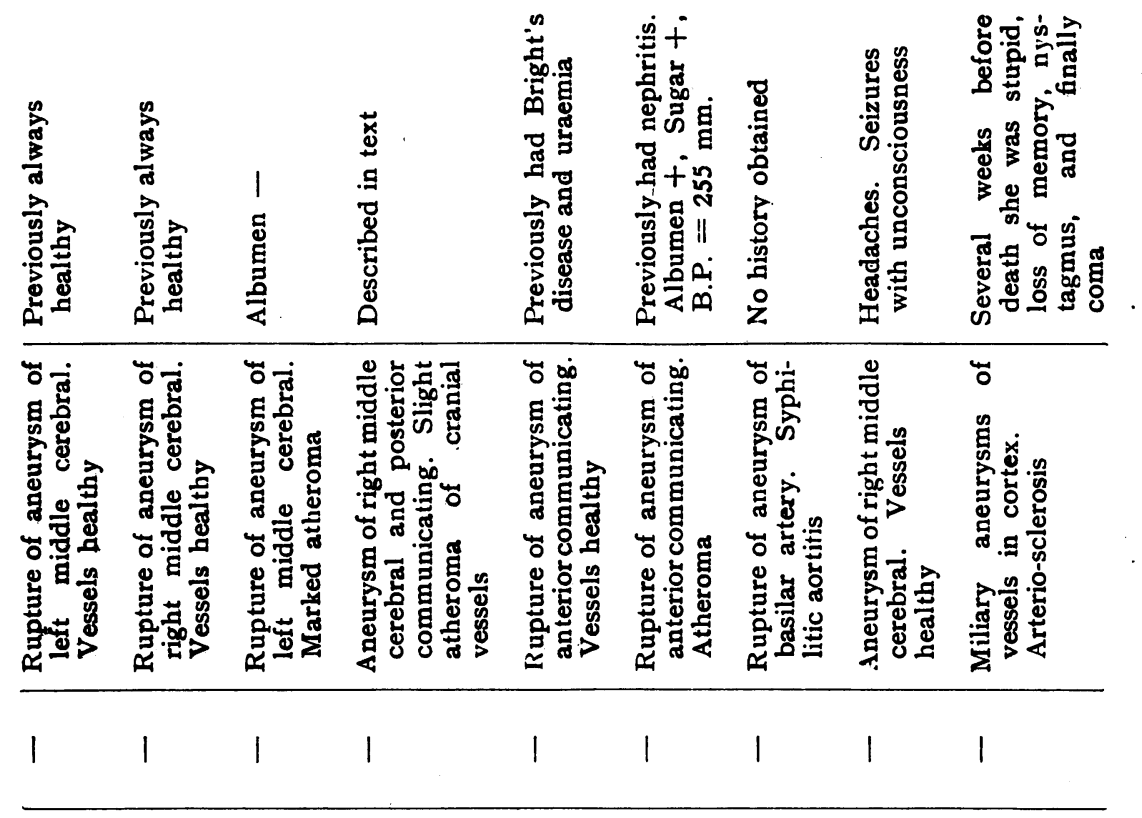

$+\quad+\quad+\quad+\quad+\quad+\quad+$

$\begin{array}{r}++1+1+1 \\ \hline\end{array}$

$+++1++1+1+$

\begin{tabular}{|c|c|c|c|c|c|c|c|c|}
\hline 1 & 1 & 1 & + & $!$ & 1 & i & l' & 1 \\
\hline$!$ & 1 & 1 & + & 1 & $i$ & 1 & + & + \\
\hline$\cong$ & $\stackrel{m}{N}$ & นก & $\stackrel{m}{\sim}$ & 요 & กั & กี & $\stackrel{\circ}{*}$ & $\neq$ \\
\hline$\Sigma$ & $\Sigma$ & ⿷ & $\Sigma$ & L & $\Rightarrow$ & $\Sigma$ & 1 & I I \\
\hline$\stackrel{0}{0}$ & 壱 & 苂 & 。임 & $\underset{\tilde{ల}}{\tilde{B}}$ & $\frac{a}{\hat{0}}$ & 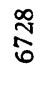 & 交 & $\stackrel{\circ}{\circ}$ \\
\hline
\end{tabular}


The British Journal of Ophthalmology

\begin{tabular}{|c|c|c|c|c|c|c|c|c|}
\hline$\frac{\bar{z}}{3}$ & 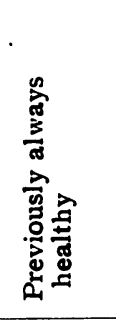 & 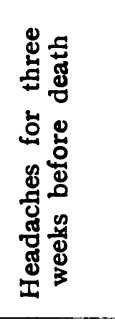 & 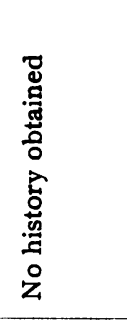 & 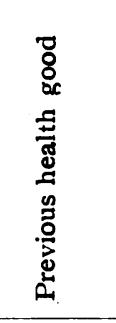 & 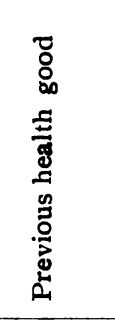 & 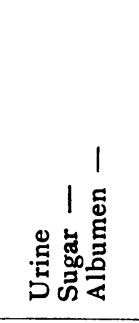 & 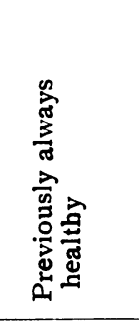 & 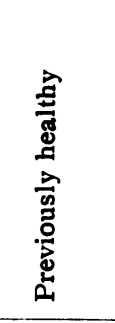 \\
\hline 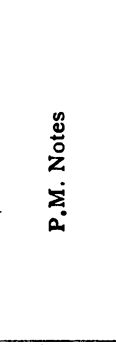 & 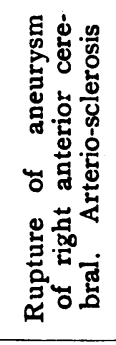 & 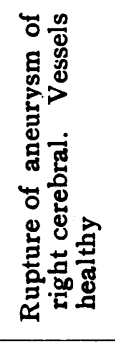 & 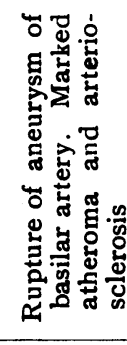 & 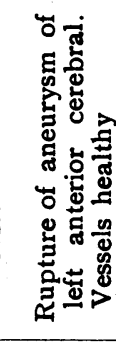 & 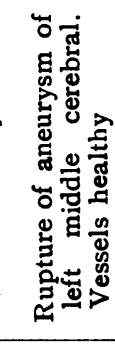 & 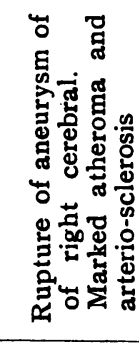 & 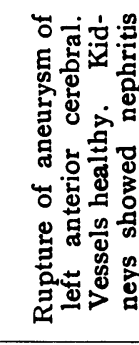 & 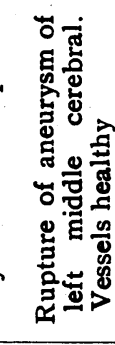 \\
\hline 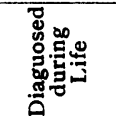 & 1 & 1 & 1 & 1 & 1 & 1 & 1 & 1 \\
\hline 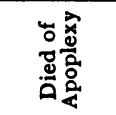 & + & + & + & + & + & + & + & + \\
\hline 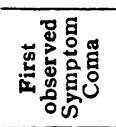 & + & 1 & + & + & + & + & + & 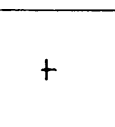 \\
\hline 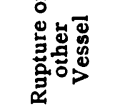 & 1 & 1 & I & 1 & 1 & 1 & 1 & 1 \\
\hline 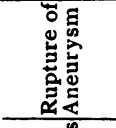 & + & + & + & + & + & + & + & + \\
\hline 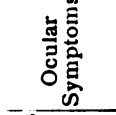 & 1 & $:$ & 1 & $i$ & $!$ & 1 & 1 & 1 \\
\hline 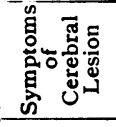 & 1 & 1 & 1 & 1 & 1 & 1 & 1 & 1 \\
\hline$\stackrel{\circ}{\circ}$ & $\approx$ & $q$ & F & F & 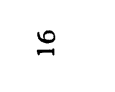 & : & $\approx$ & $\ddot{m}$ \\
\hline 今̆ & $z$ & H & \pm & $z$ & $\bar{z}$ & $z$ & 4 & 4 \\
\hline 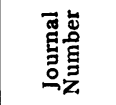 & 爱 & 亳 & $\frac{m}{n}$ & हू๊ & $\tilde{z}$ & $\stackrel{8}{8}$ & $\stackrel{+\infty}{*}$ & 虽 \\
\hline
\end{tabular}


Cerebral Aneurysm
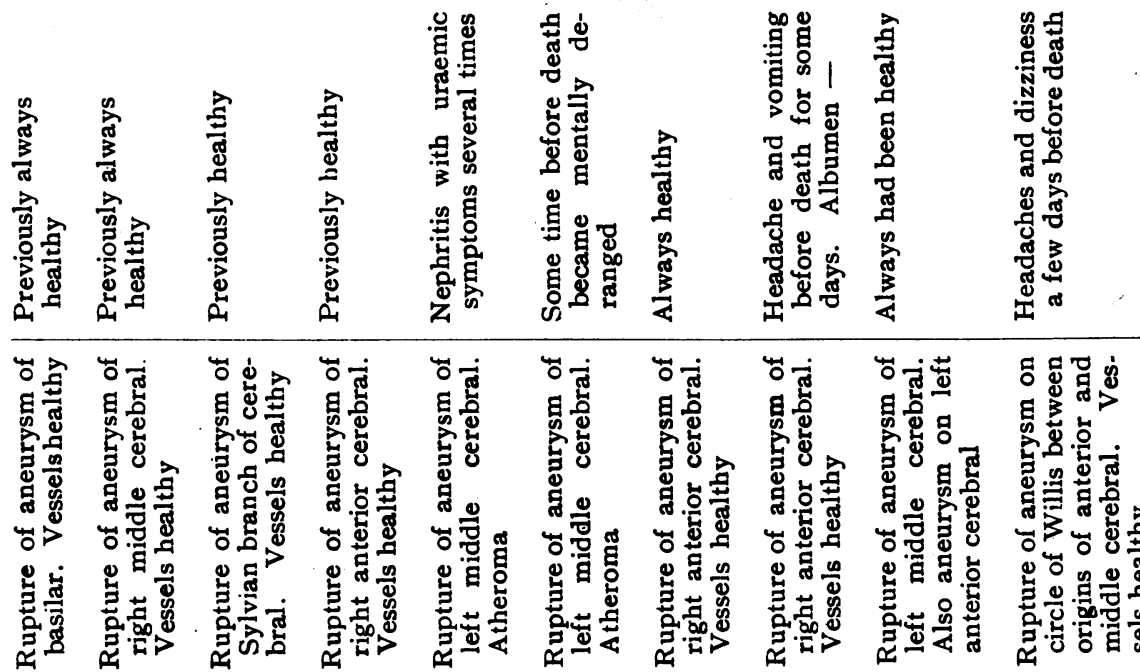

究。

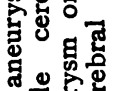

통ㅎํ

늘연

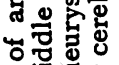

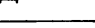

-

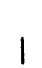

$+\quad+\quad+\quad+\quad+\quad+\quad+$

1

$+1+$

1

1

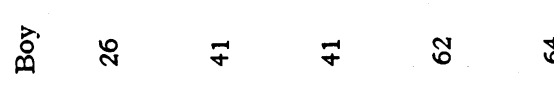

\begin{tabular}{|c|c|c|c|c|c|c|c|c|}
\hline$\Sigma$ & 'I & 山 & $\Sigma$ & L & $\Sigma$ & $\Sigma$ & W & $\Sigma$ \\
\hline 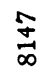 & ర్గ్ర & 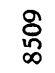 & 离 & : & : : & 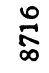 & $\underset{\infty}{\stackrel{\infty}{\infty}}$ & : \\
\hline
\end{tabular}

\begin{tabular}{|c|c|c|c|}
\hline 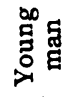 & $\stackrel{\infty}{m}$ & 뭉 & $\because$ \\
\hline$\Sigma$ & is & $\Sigma$ & I \\
\hline$\underset{\infty}{\stackrel{\circ}{\infty}}$ & $\stackrel{\circ}{\stackrel{\infty}{\infty}}$ & : & ஜू \\
\hline
\end{tabular}




\section{Conclusions}

(1) Beadles' largest class is 46 per cent., namely, those who died suddenly from an apoplectiform seizure without any preceding symptoms of cerebral origin. My figures suggest that this class includes a still larger percentage, as 29 of my 43 cases died in this manner.

(2) My records show that this is a condition that occurs frequently in youth, and tends to end fatally in the same period of life.

(3) All the pathological causes of cerebral aneurysm having been considered, some of which are atheroma, specific arteritis, embolism, heart diseases, trauma, vasomotor and other causes, we are thrown back on the theory that these dilatations of cerebral vessels are in many cases due to some congenital weakness in the vessel walls. I quote Fearnsides. "Investigators have suggested, that, in addition to certain factors such as increased blood pressure, there is an inherent inborn weakness, due to congenital abnormality in the structure of the arteries at their points of junction and bifurcation, and this leads to rupture."

(4) This study throws no new light on the symptomatology or aetiology of this condition, but it brings before us again its comparative frequency, and the necessity for a closer examination of possible cases, with a view to gaining further information on an important pathological condition.

I conclude by acknowledging my debt of thanks to Dr. Cowan and Professor Teacher, for assistance in a manner already indicated, and to Mr. Dalrymple, for two clever sketches.

\section{BIBLIOGRAPHY}

1. Osler.- " Principles and practice of medicine," 1922.

2. Newton-Pitt.-Ibid.

3. Bradford.-Lancet, Vol. II, pp. 703-706, 1908.

4. Fearnsides.-Brain, Vol. XXXIX, p. 224, 1916.

5. Bramwell.-Edin. Med. Jl., Vol. XXXII, 1886-87.

6. Weir Mitchell.-Jl. of Nervous and Mental Diseases, Vol. XVI, 1889.

7. Beadles.-Brain, Vol. XXX, 1907.

8. Oppenheim.-Text-book of Nervous Diseases, Vol. II, 1911. (English trans. by Bruce.)

9. Symonds.- "Spontaneous subarachnoid haemorrhage," Quart.Jl. Med., October, 1924.

10. Turnbull.-Brain, Vol. XLI, p. 50, 1918. 